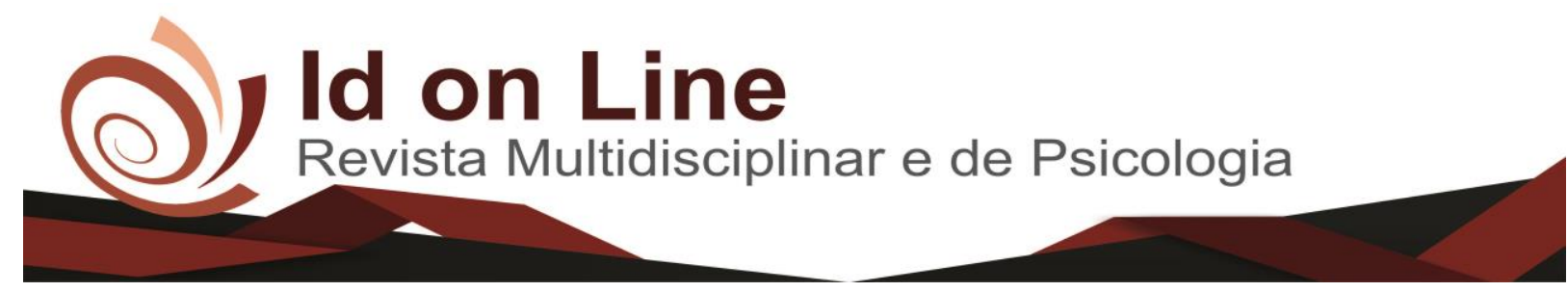

Comment

\title{
A Lei 13.146/15 em Escolas Públicas: discutindo sua efetividade nas Políticas públicas de Inclusão
}

Athena de Albuquerque Farias ${ }^{1}$, Joelma dos Santos Barbosa Linhares Garcia², Raphael Rocha Freire ${ }^{3}$

Resumo: As discussões sobre o tema Inclusão social, tem repercutido em todo o mundo, como mobilizadora de outros importantes movimentos sociais, que implicaram em ações políticas, não menos impactantes. Dessa forma, gradativamente as sociedades democráticas passaram a divulgar, discutir e defender a inclusão como direito de todos, em relação aos diversos espaços sociais. A evolução dos estudos sobre a Lei 13.146/15 são bem recentes, tendo em vista que a promulgação desta lei somente aconteceu efetivamente em 2016. Portanto há aproximadamente dois anos. As escolas são espaços responsáveis pelo processo de formação dos jovens por meio de reflexões críticas. Abrangem aspectos teóricos, técnicos, éticos e morais, que encontram-se implicados na vida em sociedade, conforme a Lei de Diretrizes e Bases da Educação Nacional (1996). Portanto, é preciso que se compreenda principalmente a ética implicada neste contexto, de forma que se promova uma vida de relacionamentos mais agradável e, compartilhada em conformidade com os valores humanos básicos, tais como solidariedade, justiça e responsabilidade.

Palavras-chave: Inclusão, políticas públicas, Educação.

\section{The Law No. 13,146 / 15 in the Public Schools: discussing its effectiveness in the Public Policies of Inclusion}

\begin{abstract}
Discussions on the theme of social inclusion have had repercussions all over the world, as a mobilizer of other important social movements, which implied political actions, no less shocking. In this way, democratic societies gradually began to divulge, discuss and defend inclusion as a right of all, in relation to the various social spaces. The evolution of the studies on Law 13146/15 are very recent, since the enactment of this law only happened effectively in 2016, approximately two years. Schools are spaces responsible for the process of training young people through critical reflections. They cover theoretical, technical, ethical and moral aspects that are implicated in life in society, according to the Law of Guidelines and Bases of National Education (1996). It is therefore necessary to understand principally the ethics involved in this context, so as to promote a more enjoyable and shared life of relationships in accordance with basic human values such as solidarity, justice and responsibility.
\end{abstract}

Keywords: Inclusion, public policies, Education.

\footnotetext{
${ }^{1}$ Advogada pela Faculdade dos Guararapes, PE. Contato: athena.farias@ gmail.com;

${ }^{2}$ Graduação em Ciências Econômicas pela Universidade Regional do Cariri; Graduação em Licenciatura Pleno em Disciplinas Específicas do Ensino Básico pela Universidade Estadual do Ceará, UECE; Especialização em Administração de Empresas pela Autarquia Educacional do Araripe - AEDA; Especialização em Metodologia do Ensino Fundamental e Médio pela Universidade Vale do Acaraú - UVA; Especialização em Docência do Ensino Superior pela Faculdade Kurius; Graduação em Direito pela Faculdade de Filosofia, Ciências e Letras de Cajazeiras; Especialização em Direito Penal pela Faculdade de Filosofia, Ciências e Letras de Cajazeiras - FAFIC; Mestrado em Ciências da Educação Universidad Politécnica Y Artística Del Paraguay (2014). Mestra em Linguística pela Universidade Federal da Paraíba - UFPB (2017). Contato: jsblinharesgarcia@hotmail.com

${ }_{3}^{3}$ Enfermeiro. Graduatdo pela Universidade Doutor Leão Sampaio - UNILEÃO, Ceará. Contato: raphaelg2@ hotmail.com.
} 


\section{Introdução}

A temática da Inclusão social tem sido marcada ultimamente no mundo inteiro, principalmente no ocidente, como uma temática importante, mobilizadora de importantes outros movimentos sociais, causadores de ações política, não menos impactantes. Dessa forma, gradativamente as sociedades democráticas passaram a divulgar, discutir e defender a inclusão como direito de todos, em relação aos diversos espaços sociais.

Boccolini (2000) acredita que algumas transformações ocorridas em pessoas, por perda de capacidades, são percebidas de uma maneira geral como limitantes, implicando em dificuldades no desempenho. Tais crenças afetam diversas tarefas do dia-a-dia. Neste contexto, a Inclusão Social passa a considerar também a satisfação com a vida, como um componente importante não apenas no contexto pessoal, mas também no educacional. Não bastando a inclusão por si, mas uma inclusão com uma característica qualitativamente melhor.

A perda de algumas capacidades por crenças limitadoras, tende a afetar diretamente o comportamento e a forma de agir da pessoa. Assim o indivíduo tende ao fracasso emocional (BOTELHO et al., 2003). As pessoas com necessidades especiais, representam um desafio ainda maior para ajustarem-se psicologicamente, ante suas condições psicofisiológicas e de saúde (EPHRAIM et al., 2003).

Apesar da Lei 13.146/15, que institui a Inclusão de pessoas com deficiência, sua efetividade precisa ser avaliada nas instituições educacionais, nas suas diversas dimensões sociais e políticas. Neste sentido, tem sido queixa recorrente o não atendimento às necessidades educacionais especiais, das pessoas com deficiência.

A Inclusão social será entendida neste estudo como uma participação ativa em grupos de convivência social, em oposição à uma completa deficiência, que seria uma perda ou anormalidade das estruturas ou de uma função corporal, de acordo com a Organização Pan Americana de Saúde (OPAS, 2003). Inclua-se aí a função psicológica.

É importante conhecer e, levar-se em conta, o quão satisfeitos com a vida, sentem-se os alunos amparados pela lei 13.146/15, participantes das diversas Escolas públicas.

Dessa forma nos indagamos: Qual a efetividade desta ação inclusiva em termos de política pública? 


\section{Responsabilidade social na efetividade da aplicação da lei}

A temática da Responsabilidade Social, onde também subjacem as questões da Inclusão Social, tem sido muito discutidas, embora não se tenha ainda chegado ao ideal, no Brasil. O grande número de publicações a esse respeito tem sido bom testemunho.

Ashley (2002), nos orienta que, responsabilidade social pode ser definida como uma obrigação de caráter moral, quando houver a necessidade de aderir a um comportamento que seja socialmente desejável, responsável e justo para com o Estado e a sociedade civil, no sentido da construção de um mundo melhor. Neste sentido, seria a responsabilidade social um compromisso de dever da sociedade, expresso através de atitudes benéficas aos seres humanos e, ao meio ambiente, de maneira a beneficiar toda uma comunidade.

As escolas são espaços responsáveis pelo processo de formação e profissionalização de crianças e jovens por meio de reflexões críticas. Aspectos teóricos, técnicos, éticos e morais, também são experienciados na escola, pois estão implicados na vida em sociedade, conforme a da Lei de Diretrizes e Bases da Educação Nacional (1996). Portanto, a ética, neste contexto, é compreendida como um desejo de uma vida agradável e compartilhada em conformidade com os valores humanos básicos, tais como solidariedade, justiça e responsabilidade (SOUSA, 2011).

Dias Sobrinho (2005, p. 28), tecendo considerações sobre a responsabilidade social enquanto Missão, assim nos orienta: "o sentido essencial da responsabilidade social da Educação consiste em produzir e socializar conhecimento que tenha não só mérito científico, mas também valor social e formativo". Pelo exposto, observe-se que, as discussões sobre responsabilidade social, implicaram na criação de estratégias de responsabilidade social, a exemplo da Lei 13.146/15 para a Educação brasileira. Daí a grande necessidade de se analisar a efetividade das ações inclusivas em termos de política pública nas escolas públicas brasileiras.

Trata-se de uma grande conquista. Uma ferramenta para que se possa exigir a garantia dos direitos do cidadão com deficiência. Esta precisa ser respeitada, permitindo, finalmente, que tais pessoas possam se defender, de forma concreta, de qualquer mecanismo de exclusão, preconceito ou discriminação, quanto ao acesso em todos os setores sociais.

Esta lei torna crime, punível com reclusão entre dois e cinco anos, além de multa, a saber: "recusar, cobrar valores adicionais, suspender, procrastinar, cancelar ou fazer cessar 
inscrição de aluno em estabelecimento de ensino de qualquer curso ou grau, público ou privado, em razão de sua deficiência”, conforme descrito no seu Artigo $8^{\circ}$.

Algumas escolas particulares têm buscado formas de revogar tal determinação, utilizando-se do argumento de que os estudantes possuidores de deficiência,m cria despesas extras muito específicas, necessitando assim de um acompanhamento pedagógico muito especializado.

A Lei Brasileira de Inclusão, objeto do presente comment, aparece para fortalecer as pessoas com deficiência, também através do Auxílio Inclusão. Este disponibiliza um Benefício de Prestação Continuada (BPC), em forma de ajuda financeira através do governo federal, sem abrir mão de outras oportunidades no mercado de trabalho. Observe-se que, além de garantir maior dignidade através do poder de consumo, é o trabalho, uma importante opção de integração social.

Portanto, torna-se fundamental a compreensão do que determina a Lei Brasileira de Inclusão, sobre a exigência do cumprimento de todos os seus itens.

As políticas Assistencial e Previdenciária foram as primeiras a enfrentar o desafio quanto a avaliação da deficiência para além do paradigma biomédico. Tal forma de pensar, inovou no conceito de funcionalidade como principal diretriz que, enfim, substituiria a centralidade nos aspectos biológicos e corporais.

\section{Considerações finais}

Não há como duvidar que, um dos principais desafios em se avaliar a efetividade das medidas propostas na lei da inclusão, está em se assegurar materialmente e em termos estruturais, a perspectiva da sua efetiva funcionalidade. Esta, dependeria da compreensão do papel de certas barreiras, bem como dos fatores ambientais e de como estes estão sendo promovidos pelo governo federal. Esta avaliação dos Fatores Ambientais e de possíveis barreiras à implementação efetiva das medidas previstas na lei, é o que possibilitará a descrição da deficiência como fazendo parte da promoção da igualdade e da justiça social, não somente como um tema relacionada à área da medicina.

O desafio de trazer uma perspectiva biopsicossocial para uma melhor avaliação da deficiência para o reconhecimento de direitos, na forma da Lei Brasileira de Inclusão de 2015, 
passa necessariamente pela avaliação das barreiras e pelo aperfeiçoamento das estratégias de eliminá-las, de forma a promover uma maior autonomia das pessoas com deficiência.

\section{Referências}

ASHLEY, P. A. (Coord.) Ética e responsabilidade social nos negócios. São Paulo: Saraiva, 2004.

BOCCOLINI, F. Reabilitação amputados, amputações, próteses. São Paulo: Robe Editorial, 2000.

BOTELHO, P. Linguagem e letramento na educação de surdos: ideologias e práticas pedagógicas. Belo Horizonte: Autêntica, 2003.

DIAS SOBRINHO, J. Educação Superior, globalização e democratização. Qual universidade? Revista Brasileira de Educação, 28, 164-173, 2005.

EPHRAIM, P.L.; DILLINGHAM, T.R.; SECTOR, M.; PEZZIN, L.E. E MACKENZIE, E.J. Epidemiology of Limb Loss and Congenital Limb Deficiency: a review of the literature. Arch. Physical Med. Rehabilitationl, 84, 747-761, 2003.

Lei n. 9.394, de 20 de dezembro de 1996. (1996, 23 de dezembro). Estabelece as Diretrizes e Bases da Educação Nacional. Diário Oficial da União, seção 1. Brasília, DF, 1996.

Organização Pan-Americana da Saúde. Saúde, Bem-estar e Envelhecimento - O Projeto Sabe no município de São Paulo: uma abordagem inicial. Brasília: OPAS; 2003.

SOUSA, M. do A. Desenvolvimento humano no contexto do voluntariado: interfaces com a ética e a sustentabilidade. Tese de Doutorado, Instituto de Psicologia, Universidade de Brasília, Brasília, DF, 2011.

Como citar este artigo (Formato ABNT):

FARIAS, Athena de A.; GARCIA, Joelma dos S.B.L.; FREIRE, Raphael R. A Lei 13.146/15 em Escolas Públicas: discutindo sua efetividade nas Políticas públicas de Inclusão. Id on Line Revista Multidisciplinar e de Psicologia, 2017, vol.11, n.38, p.920-924. ISSN: 1981-1179.

Recebido: 15.11 .2017

Aceito: 25.11 .2017 